Applied Remote Sensing

\title{
Multitemporal crop surface models: accurate plant height measurement and biomass estimation with terrestrial laser scanning in paddy rice
}

Nora Tilly

Dirk Hoffmeister

Qiang Cao

Shanyu Huang

Victoria Lenz-Wiedemann

Yuxin Miao

Georg Bareth 


\title{
Multitemporal crop surface models: accurate plant height measurement and biomass estimation with terrestrial laser scanning in paddy rice
}

\author{
Nora Tilly, ${ }^{\text {a,b,* }}$ Dirk Hoffmeister, ${ }^{\text {a,b }}$ Qiang Cao, ${ }^{\text {b,c }}$ Shanyu Huang, \\ Victoria Lenz-Wiedemann, ${ }^{\text {a,b }}$ Yuxin Miao, ${ }^{\text {b,c }}$ and Georg Bareth ${ }^{\text {a,b }}$ \\ ${ }^{a}$ University of Cologne, Institute of Geography (GIS \& Remote Sensing Group), \\ Albertus-Magnus-Platz, 50923 Cologne, Germany \\ ${ }^{b}$ International Center for Agro-Informatics and Sustainable Development \\ ${ }^{\mathrm{c} C h i n a}$ Agricultural University, Department of Plant Nutrition, \\ 100193 Beijing, China
}

\begin{abstract}
Appropriate field management requires methods of measuring plant height with high precision, accuracy, and resolution. Studies show that terrestrial laser scanning (TLS) is suitable for capturing small objects like crops. In this contribution, the results of multitemporal TLS surveys for monitoring plant height on paddy rice fields in China are presented. Three campaigns were carried out on a field experiment and on a farmer's conventionally managed field. The high density of measurement points allows us to establish crop surface models with a resolution of $1 \mathrm{~cm}$, which can be used for deriving plant heights. For both sites, strong correlations (each $R^{2}=$ 0.91 between TLS-derived and manually measured plant heights confirm the accuracy of the scan data. A biomass regression model was established based on the correlation between plant height and biomass samples from the field experiment $\left(R^{2}=0.86\right)$. The transferability to the farmer's field was supported with a strong correlation between simulated and measured values $\left(R^{2}=0.90\right)$. Independent biomass measurements were used for validating the temporal transferability. The study demonstrates the advantages of TLS for deriving plant height, which can be used for modeling biomass. Consequently, laser scanning methods are a promising tool for precision agriculture. (C) The Authors. Published by SPIE under a Creative Commons Attribution 3.0 Unported License. Distribution or reproduction of this work in whole or in part requires full attribution of the original publication, including its DOI. [DOI: 10.1117/1.JRS.8.083671]
\end{abstract}

Keywords: terrestrial laser scanning; plant height; growth; biomass; rice; precision agriculture; crop monitoring; field level.

Paper 13392 received Oct. 11, 2013; revised manuscript received Jan. 15, 2014; accepted for publication Jan. 31, 2014; published online Mar. 6, 2014.

\section{Introduction}

The cultivation of rice is increasingly important in consequence of its role as a staple food, in particular for the rapidly growing Asian population. In 2011, about $90 \%$ of the estimated world rice production, about 650 million tons, was produced in Asia. ${ }^{1}$ Due to a further growing population with a constant or even decreasing cultivation area, a field management aiming at high production and sustainability of natural resources is required. Main goal is to close the gap between potential and current yield in developed and developing countries. ${ }^{2}$ Therefore, in the context of precision agriculture, accurate crop monitoring should be based on the remote and proximal sensing for improving the relationship between inputs and outputs. $^{3}$

Rice grain yield, for example, is positively correlated to biomass and nitrogen $(\mathrm{N})$ translocation efficiency. ${ }^{4}$ However, the over-fertilization with $\mathrm{N}$ by farmers is a major problem for soil and groundwater. Hence, ways for enhancing the field management are necessary.

*Address all correspondence to: Nora Tilly, nora.tilly@uni-koeln.de 
Overviews about the actual situation and recent trends in China are given in Refs. 5 and 6 .

Considering that the biomass production of crops can be described as a function of $\mathrm{N}$ content, an optimal fertilization requires the knowledge about the suitable $\mathrm{N}$ content of the plants as well as the methods of determining the actual $\mathrm{N}$ content and the biomass. ${ }^{7-9} \mathrm{~A}$ widely used indicator for quantifying the actual status is the nitrogen nutrition index (NNI), as the ratio between measured and critical $\mathrm{N}$ content. ${ }^{10-12}$ The critical $\mathrm{N}$ content is determined by the $\mathrm{N}$ dilution curve, which represents the relationship between $\mathrm{N}$ concentration and biomass.

In order to estimate the values for the calculation of the NNI, the use of nondestructive remote sensing technologies is in the focus of research. Several studies exist using a chlorophyll meter, ${ }^{13,14}$ a hand-held spectro-radiometer, ${ }^{15-17}$ or an airborne hyperspectral sensor ${ }^{18}$ for determining the $\mathrm{N}$ content of rice plants. Moreover, various approaches are presented for assessing the actual biomass. Spaceborne data are commonly used due to the usually wide areal extent of paddy rice fields. ${ }^{19-21}$ In addition, satellite remote sensing images enable the estimation of rice yield based on the calculation of vegetation indices. ${ }^{22,23}$

Higher spatial and temporal resolutions are required for estimating the biomass more precisely and within-field variability. Few works on the virtual modeling of rice plants in a high resolution exist, ${ }^{24,25}$ but the complex plant structure and growing process cause uncertainties about the transferability to the field. Thus, in situ measurements for biomass estimation are useful. In an early approach, the biomass of rice was predicted from reflectance data, measured with a hand-held radiometer. ${ }^{26}$ Similar results are reported in Refs. 27 and 28. In Ref. 29, the authors used an active hand-held optical reflectance sensor for monitoring the rice canopy during the growing period and developed a precise $\mathrm{N}$ management strategy. Furthermore, the authors in Ref. 30 emphasized that rice plant height is a key factor for predicting yield potential and established a model for estimating the plant height increase, but methods for accurate in situ determination are rare.

Besides hyperspectral and optical sensors, the technology of light detection and ranging (LIDAR) became increasingly important in a wide range of research fields, including the acquisition of vegetation parameters. Advantages of airborne and ground-based LIDAR remote sensing for ecosystem studies are highlighted in Refs. 31 and 32. Tremendous research is conducted in forestry applications. ${ }^{33-38}$ The main benefits are the fast and accurate data capturing, the high point density data, and therefore the highly realistic representation.

Several crops were already investigated with ground-based LIDAR approaches for various purposes, for example, measuring height of perennial grass ${ }^{39}$ or biomass of grapevine, ${ }^{40}$ oilseed rape, winter rye, winter wheat, and grassland. ${ }^{41,42}$ Furthermore, estimating crop density, ${ }^{43,44}$ nitrogen status, ${ }^{45}$ and leaf area index ${ }^{46}$ of wheat, or detecting spatial and temporal changes of different sugar beet cultivars ${ }^{47}$ are evaluated. Single plant detection is possible based on the analysis of the measured intensity values. ${ }^{47,48}$ In Ref. 49 , the authors examined the use of a portable scanner in combination with a mirror for assessing the vertical plant area density in a rice canopy and achieved good results. They used the density values for estimating the dry weight of plant organs (ears, leaves, and stems). As stated in Ref. 50, terrestrial laser scanning (TLS) is a promising method for estimating the biomass of small grain cereals like barley, oat, and wheat.

In this study, multitemporal crop surface models (CSMs) were established for determining the plant height from TLS measurements on paddy rice fields at different growing stages. CSMs are introduced in Ref. 51 for deriving spatial crop growth patterns on field level. Manual measurements were performed for validating the TLS measurements. In addition, the CSMs are used for estimating the actual crop biomass. Therefore, a regression model based on the findings from a field experiment was established. The model was used for estimating the biomass of rice plants on a farmer's field on the base of multitemporal CSMs.

The presented research is part of the activities of the International Center for AgroInformatics and Sustainable Development (ICASD). It was founded in 2009 as an open, international, and multidisciplinary cooperative research center. ICASD founding members are the Department of Plant Nutrition of the China Agricultural University in Beijing and the Institute of Geography at the University of Cologne, Germany (www.ICASD.org). 


\section{Materials and Methods}

\subsection{Study Area}

The surveys were conducted in the area of the city of Jiansanjiang ( $\left.47^{\circ} 15^{\prime} 21^{\prime \prime}, \mathrm{E} 132^{\circ} 37^{\prime} 43^{\prime \prime}\right)$ in Heilongiiang Province in the far northeast of China (Fig. 1). The province with a continental monsoon climate is an important basis for agricultural products in China. ${ }^{52}$ Situated in the east of Heilongjiang, the Sanjiang Plain covers almost $100,000 \mathrm{~km}^{2}$, which is about $\frac{1}{4}$ of the provinces' total area. Cold and dry winters and short but warm, humid summers are characteristic for the middle temperate and humid climate of the Sanjiang Plain, which is marked by the East Asian summer monsoon. ${ }^{53,54}$ The field campaigns were carried out at two sites: (1) a field experiment at the Keyansuo experiment station (Fig. 1) where various treatments for the cultivation of rice were applied and (2) a farmer's field (Fig. 1) with a conventional management.

\subsubsection{Field experiment}

At the Keyansuo experiment station, various field management approaches for irrigated rice cultivation were investigated in small-scale fields. The focus of the field experiment examined in this contribution was on different $\mathrm{N}$ fertilizer treatments. Differences in plant height and biomass were expected, related to the amount of $\mathrm{N}$ input. For the presented monitoring approach, this variation is useful for capturing different plant conditions at one growing stage.

One half of the field experiment with a spatial extent of $60 \mathrm{~m} \times 63 \mathrm{~m}$ was cultivated with the rice variety Kongyu 131, the other half with Longjing 21 . The plants that sprout in a greenhouse were transplanted between the 17th and 20th of May and harvested on the 20th of September 2011. Nine different treatments were repeated thrice for both rice varieties. Thus, the area was divided into 54 plots, each about $10 \mathrm{~m} \times 7 \mathrm{~m}$ in size. As shown in Table 1, the treatments differ in the amount of applied $\mathrm{N}$ fertilizer during the growing period. The amount of fertilizer was predefined for five treatments, whereas the amount for treatment 6 to 9 was adjusted based on in-season $\mathrm{N}$ content analysis. The content was approximated based on spectral reflectance measurements, performed with GreenSeeker ${ }^{\mathrm{TM}}$ (Ntech Industries, Ukiah, California, USA) and Crop Circle ${ }^{\mathrm{TM}}$ (Holland Scientific, Lincoln, Nebraska) and the actual biomass, which was measured destructively several times within the vegetation period. A detailed description of the experimental design is given in Ref. 55 .

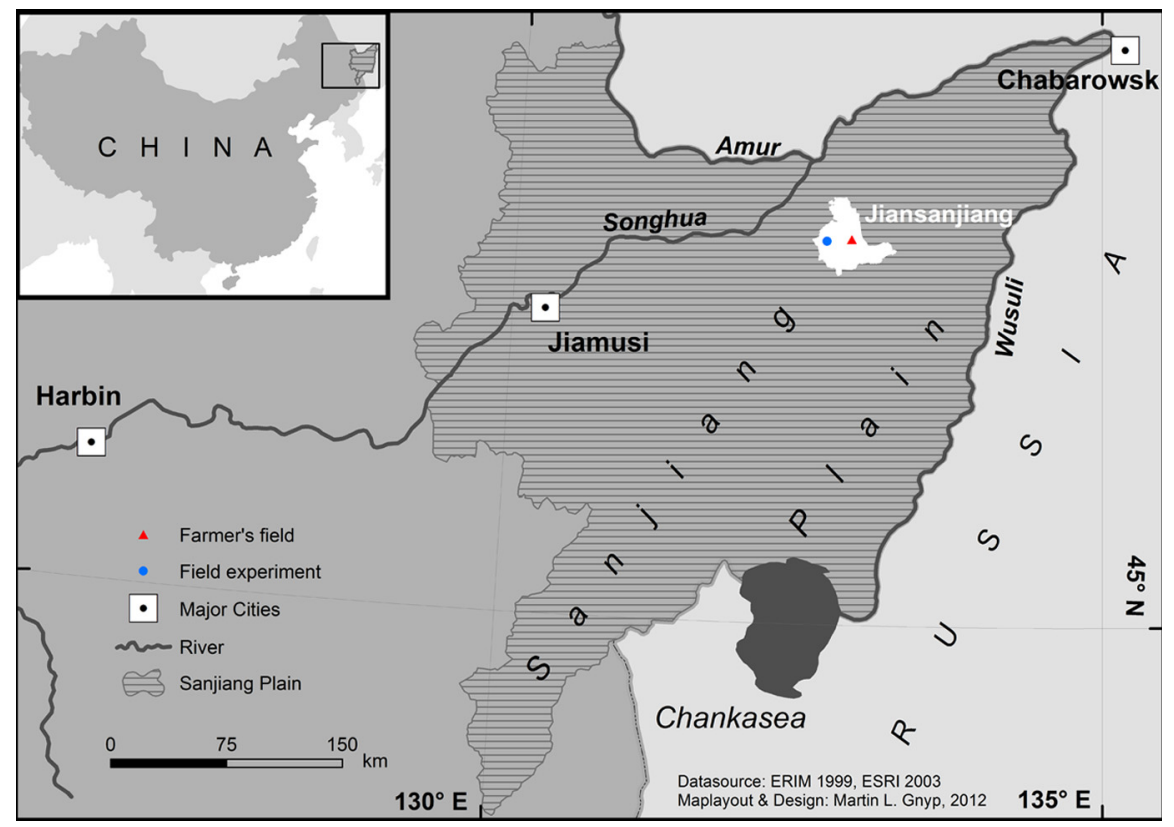

Fig. 1 Location of the study sites in China (modified from Ref. 27). 
Tilly et al.: Multitemporal crop surface models: accurate plant height measurement and biomass estimation...

Table 1 Fertilizer application scheme for both study sites.

\begin{tabular}{|c|c|c|c|c|c|}
\hline Treatment & $\begin{array}{c}\text { Base } \\
N(\mathrm{~kg} / \mathrm{ha})\end{array}$ & $\begin{array}{l}\text { Topdressing } 1 \\
(\mathrm{~kg} / \mathrm{ha})\end{array}$ & $\begin{array}{l}\text { Topdressing } 2 \\
(\mathrm{~kg} / \mathrm{ha})\end{array}$ & $\begin{array}{l}\text { Topdressing } 3 \\
(\mathrm{~kg} / \mathrm{ha})\end{array}$ & $\begin{array}{c}\text { Total } \\
\mathrm{N}(\mathrm{kg} / \mathrm{ha})\end{array}$ \\
\hline \multicolumn{6}{|c|}{ Field Experiment } \\
\hline Date & May 6, 2011 & May 30, 2011 & July 09-21, 2011 & July 29, 2011 & \\
\hline 1 & 0 & 0 & 0 & 0 & 0 \\
\hline 2 & 28 & 14 & 19.6 & 8.4 & 70 \\
\hline 3 & 40 & 20 & 28 & 12 & 100 \\
\hline 4 & 52 & 26 & 36.4 & 15.6 & 130 \\
\hline 5 & 64 & 32 & 44.8 & 19.2 & 160 \\
\hline 6 to 8 & 40 & 20 & $N / A^{a}$ & $N / A^{a}$ & $N / A^{b}$ \\
\hline 9 & $40+55 \mathrm{SCU}^{\mathrm{c}}$ & 0 & $N / A^{a}$ & 0 & $N / A^{b}$ \\
\hline \multicolumn{6}{|c|}{ Farmer's field } \\
\hline \multirow[t]{2}{*}{ Date } & April 14-16, 2011 & May 29, 2011 & June 9, 2011 & July 8, 2011 & \\
\hline & 40 & 12 & 18 & 30 & 100 \\
\hline
\end{tabular}

\subsubsection{Farmer's field}

The aim of investigating a farmer's conventionally managed field was to provide an independent validation dataset and check the transferability of the findings from the field experiment described above. For this purpose, a farmer's field with similar growing pattern but a considerably larger spatial extent of $300 \mathrm{~m} \times 500 \mathrm{~m}$ was chosen. The plants also sprouted in a greenhouse were transplanted on the 17th and 18th of May, and harvested between the 25th of September and 10th of October 2011. Unfortunately, it was not possible to find any field with one of the rice varieties investigated at the Keyansuo experiment station, where the farmer would have allowed us to enter the rice paddies and to take destructive samplings several times within the growing season. The field was cultivated with the rice variety Kenjiandao 6 . The dates of fertilization differ from the field experiment (Table 1).

\subsection{TLS Measurements}

The chosen survey period of late June to July captures the key vegetative stage of the rice plants, when the stem elongation process takes place. Remarkable differences in plant development occur due to the increase of tillers and plant height during this stage. For the monitoring approach, three campaigns were carried out on both fields, which were each time conducted on two consecutive days. The campaign dates are given in Table 2.

For all field campaigns, the terrestrial laser scanner Riegl VZ-1000, ${ }^{56}$ provided by Five Star Electronic Technologies located in Beijing, was used. The scanner operates with the time-offlight technique, where the time between transmitting and receiving a pulsed laser signal is measured. The time is used for calculating the distance between the sensor and target. Parallel scan lines are achieved with a rotating multifacet polygon mirror and the rotation of the scanners head itself, which implies a wide field of view, up to $100 \mathrm{deg}$ in vertical and $360 \mathrm{deg}$ in horizontal direction. The infrared laser beam has a high precision of $5 \mathrm{~mm}$ and an accuracy of $8 \mathrm{~mm}$. Apart from a measurement rate of up to 122,000 points/s, long range distance measurements of up to $1400 \mathrm{~m}$ are possible. In addition, the system is capable of an online full-waveform analysis and according to echo digitization. 
Tilly et al.: Multitemporal crop surface models: accurate plant height measurement and biomass estimation. . .

Table 2 Dates of the scan campaigns and corresponding phenological stages.

\begin{tabular}{lccc}
\hline \hline Date & Field & Variety & BBCH-scale \\
\hline June 21, 2011 & Experiment & Kongyu 131 & 13 \\
& & Longjing 21 & 13 \\
June 22, 2011 & Farmer's & Kenjiandao 6 & 13 \\
July 4, 2011 & Experiment & Kongyu 131 & 13 to 15; 22 to 23 \\
& & Longjing 21 & 13 to 15; 22 to 23 \\
July 5, 2011 & Farmer's & Kenjiandao 6 & $13 ; 21$ \\
July 18, 2011 & Experiment & Kongyu 131 & $19 ; 29 ; 32$ \\
July 19, 2011 & & Longjing 21 & $19 ; 29 ; 32$ \\
\hline \hline
\end{tabular}

aultiple values due to several samples.

Additionally, a digital camera, Nikon D700, was mounted on the laser scanner. From the recorded RGB-photos, the point clouds gained from the laser scanner can be colorized, resulting in three-dimensional RGB point clouds and the corresponding surfaces can be textured. The camera was connected to the scanner for adjusting the camera settings and ensuring an accurate alignment between the devices. During the acquisition, the whole system was remotely controlled with the RiSCAN Pro Software on a notebook, linked via an LAN connection.

During the campaigns at the field experiment, the scanner was fixed on a tripod which raised the sensor up to $1.5 \mathrm{~m}$ above ground. Where possible, a small trailer behind a tractor was used for achieving a greater height of about $3 \mathrm{~m}$ (Fig. 2). The study area was scanned from nine scan positions for capturing all fields of the Keyansuo experiment station and minimizing shadowing effects. Although the data from all positions were used for the analysis, four of them were of major importance, as they were located closely to the investigated $\mathrm{N}$ field experiment. Two positions were accomplished without the trailer at the north edge and two positions with the trailer at the south edge of the field. The whole setting is shown in Fig. 3.

On the farmer's field (Fig. 4), the scanner was also mounted on the tripod. Accordingly, the sensor height was about $1.5 \mathrm{~m}$ above ground. Due to a limited access on the small dikes between the plots, it was impossible to use a trailer or to reach any lifted position. The field was scanned from seven scan positions. For this study, the whole field is divided into the overall field and two intensively investigated units (W and E in Fig. 4). In order to get a high resolution for the latter ones, four scan positions were placed at their corners. Twelve thin, long bamboo sticks per unit were stuck in the ground, placed in an equally spaced grid, which can be detected in the point clouds and located in the field to ensure the spatial linkage to other plant parameter measurements. An additional grid with 28 measurement points represented by bamboo sticks was placed in the overall field.

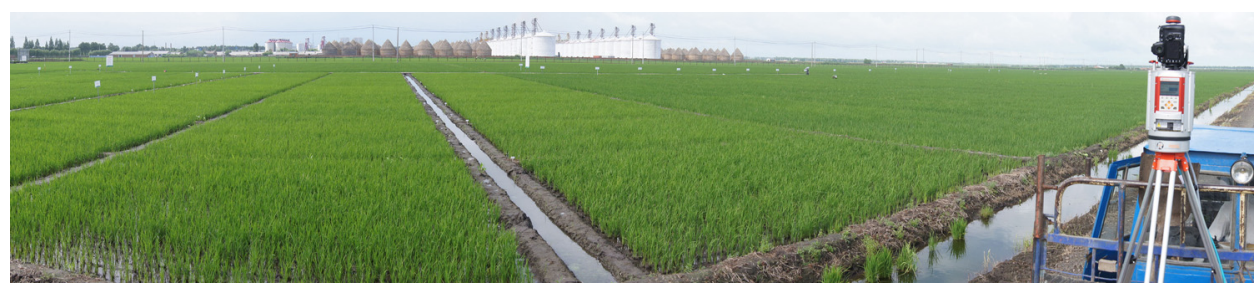

Fig. 2 Overview of the investigated field experiment from scan position six (Fig. 3). On the right side the scanner with the tripod mounted on the small trailer can be seen (taken: July 4, 2011). 
Tilly et al.: Multitemporal crop surface models: accurate plant height measurement and biomass estimation...

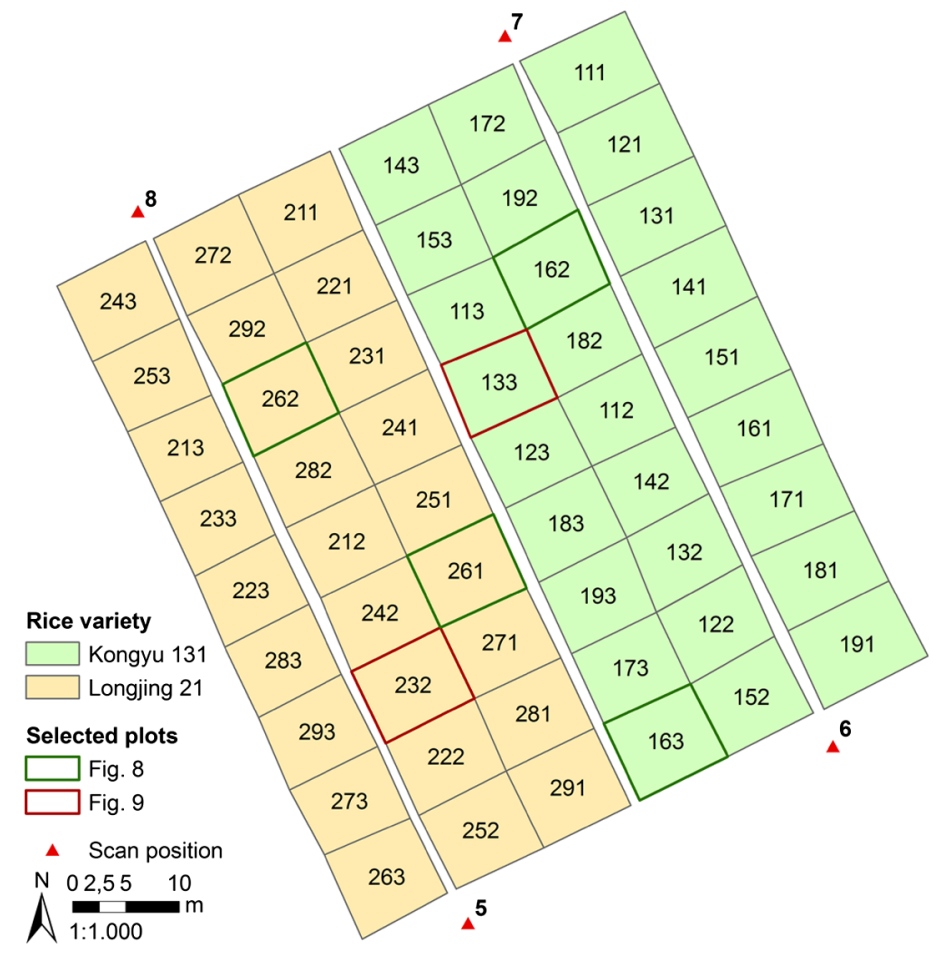

Fig. 3 Experimental design and scan positions of the field experiment. Number in the plot represents rice variety ( $1=$ Kongyu $131 ; 2=$ Longjing 21 ); treatment ( 1 to 9 in Table 1 ); and repetition (1 to 3 ).

Common tie points in all scans of each site are required to enable the merging of all scan positions in the postprocessing. Therefore, high-reflective cylinders, which can be easily detected by the laser scanner, were fixed on ranging poles built upon the dikes between the fields. ${ }^{51}$ The reflectors had to be detected from all scan positions for computing the spatial relationship between all positions of the scanners and the cylinders. In the first TLS campaigns, the

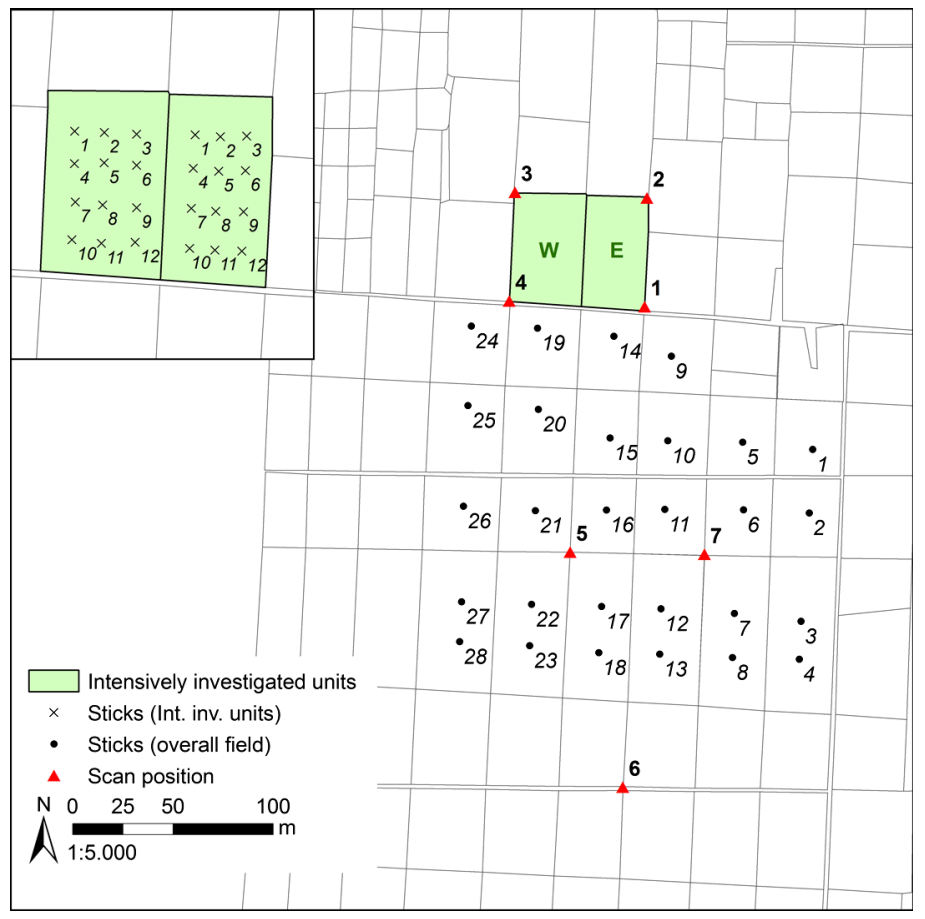

Fig. 4 Experimental design and scan positions of the farmer's field. 
Tilly et al.: Multitemporal crop surface models: accurate plant height measurement and biomass estimation...

position of each pole was marked in the fields. All scans of each date from a respective field can be merged together by re-establishing the ranging poles for the other campaigns.

\subsection{Manual Measurements}

During the whole vegetation period, manual measurements were performed at both sites for monitoring the development of the rice plants. The phenological stage of the plants and, more precisely, the steps in the plant development are defined here by the BBCH-scale. ${ }^{57}$ The abbreviation BBCH was derived from Biologische Bundesanstalt (German Federal Biological Research Centre for Agriculture and Forestry), Bundessortenamt (German Federal Office of Plant Varieties), and Chemical Industry, who funded the development of the scale. For both sites, the BBCH-values at the campaign dates are given in Table 2. The similar values confirm the comparable phenological development of the rice plants on the field experiment and the farmer's field.

Corresponding to each TLS campaign, plant heights were manually measured. On the field experiment, 8 to 10 hills per plot were regarded. Each hill consists of 4 to 6 rice plants. ${ }^{55}$ In both intensively investigated units of the farmer's field, the heights of four hills around each bamboo stick were measured.

As mentioned above, destructive biomass sampling was performed several times during the vegetation period at the field experiment. Samples were taken from both varieties for the respective three repetitions of treatment 1 to $5(n=30)$. Due to the small plot size, it was not feasible to take additional samples corresponding to the TLS campaigns. As the dates of sampling differ from the TLS campaign dates, the biomass values were linearly interpolated.

On the farmer's field, the four hills around each bamboo stick in the two intensively investigated units were destructively taken after the TLS measurements for measuring the biomass $(n=24)$. After each campaign, the grid of bamboo sticks was moved for having an undisturbed area around the bamboo sticks for the following campaign. Furthermore, in the overall field destructive samplings were taken around the mentioned 28 bamboo sticks on the 26th of June, as an additional independent validation dataset (Fig. 4). For all samplings, the cleaned above ground biomass was dried in a compartment dryer and weighed after dehydrating. The average dry biomass per $\mathrm{m}^{2}$ was calculated, considering the number of hills per $\mathrm{m}^{2}$, which was counted in the field corresponding to each sampling.

\subsection{TLS Data Processing}

The general workflow for the postprocessing of the TLS data is shown in Fig. 5. It consists of the (1) registration and merging of all point clouds, (2) filtering and extraction of the area of interest (AOI), (3) spatial, and (4) statistical analyses, considering the manual measurements.

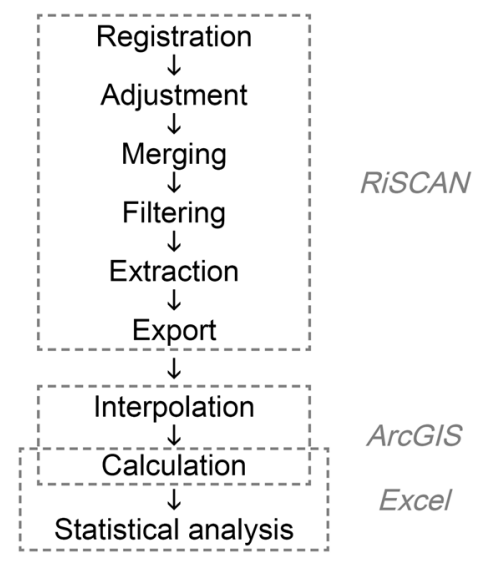

Fig. 5 General overview of the workflow for the postprocessing of the terrestrial laser scanning data. 
The first steps ( 1 and 2 ) were carried out directly in Riegl's software RiSCAN Pro, which was already used for the data acquisition. First of all, the scans from the respective three campaigns were imported into one RiSCAN Pro project. The registration of the scan positions was executed with an indirect registration method, based on the above mentioned high-reflective cylinders acting as tie points. With an automatic algorithm, corresponding tie points between the scan positions can be found. After the registration, the datasets still showed alignment errors, due to nonoptimal reflector positioning, imprecise re-establishing of the ranging poles, or instabilities during the measurements. A further adjustment was applied to minimize these errors. RiSCAN Pro offers the Multistation Adjustment, which is based on the iterative closest point algorithm. ${ }^{58}$ The position and orientation of each scan position were modified in multiple iterations for getting the best fitting result for all of them.

The point clouds still contained noise, caused by reflections on water in the field or on small particles in the air. Thus, a further filtering based on the reflectance, measured for each point during the data acquisition, was performed. Points under a certain reflectance value, regarded as noise, were removed. As the reflectance value depends on the distance from the sensor to the field as well as other factors, the critical value was slightly different for each scan.

Subsequently, all point clouds of each respective date were merged to one dataset and the AOI was manually extracted. For an easier orientation and the distinction between fields and dikes, the point clouds were previously colorized from the recorded pictures. The AOI was further separated for each date and plot to have a common spatial base. A filtering scheme was used for selecting the maximum points and determining the crop surface. Finally, those filtered point clouds were exported as American Standard Code for Information Interchange (ASCII) files for spatial and statistical analyses.

\subsection{Spatial Analysis}

ArcGIS Desktop 10 by Esri was used for constructing the CSMs and following spatial analyses. The exported ASCII files were converted to vector point data and interpolated with the inverse distance weighting (IDW) algorithm for receiving a raster representing a digital surface model with a consistent spatial resolution of $1 \mathrm{~cm}$. IDW is a deterministic, exact interpolation method, and retains a measured value at its sample location. ${ }^{59}$ Hence, the method is suitable for preserving the accuracy of measurements with a high density, like the TLS point clouds.

A common reference surface is required for the calculation of the plant heights. Usually a high-accurate digital elevation model (DEM) is used; achievable from scanning the AOI without any vegetation. ${ }^{51}$ Since it was not possible to obtain such data in this study, another method was applied: the lowest parts in the point clouds from the first date, accordingly containing the least

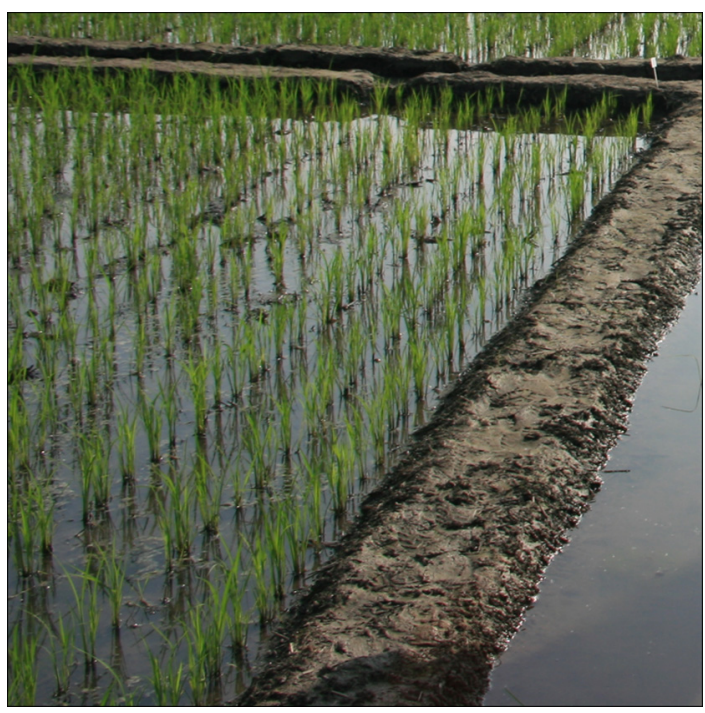

Fig. 6 Corner of the field experiment showing the least dense vegetation (taken: June 21, 2011). 


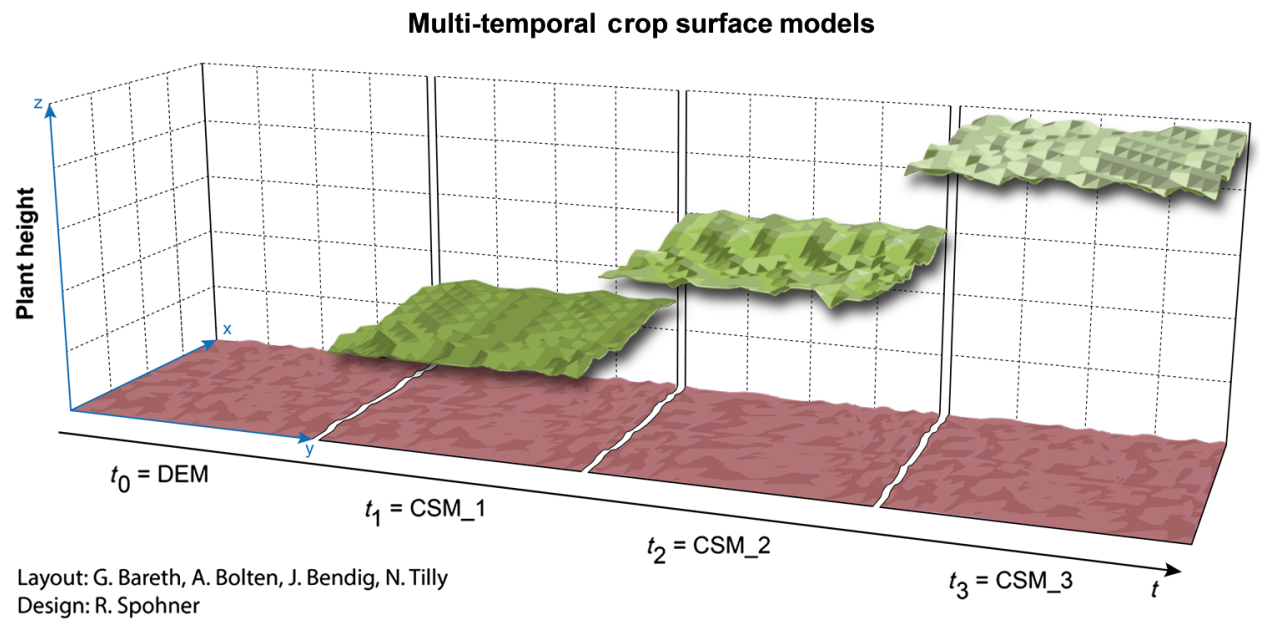

Fig. 7 General concept of crop surface models (CSMs) (Ref. 61).

dense vegetation, were manually selected for interpolating a DEM surface representing the real ground. As it can be seen in Fig. 6, the rice plants were small enough for clearly identifying points on the ground and the water height in the irrigated field was $<4 \mathrm{~cm}$ at this stage. Hence, enough ground points at the edges and around the hills remained for interpolating a DEM.

Finally, the CSMs, introduced in Ref. 51 for plant growth monitoring at field level, were established for each date. The application of CSMs is presented in Ref. 60. A CSM represents the crop surface with high spatial resolution at one campaign date, gained from the merged and filtered point cloud. As shown in Fig. 7 (Ref. 61), CSMs are used for determining the actual plant height for a given growing stage. Therefore, the DEM from the first acquisition date, representing the ground, is subtracted from the CSM, representing the crop surface. The result is the plant height above ground with the same spatial resolution as the CSMs, which is visualized in maps of plant height. By subtracting a CSM of an earlier date from a CSM of a later date, the plant growth between the dates can be spatially measured, e.g., CSM_2 minus CSM_1 in Fig. 7. The spatial patterns of the plant growth are visualized in maps of plant growth. In the following, plant growth is always defined as the spatio-temporal difference in height.

\subsection{Statistical Analysis}

The statistical analyses were performed in Microsoft Excel 2010. For a better visualization, diagrams were plotted in OriginPro 8.5 by OriginLab. The plant height values, calculated pixel-wise for the CSMs, were averaged for each plot of the field experiment and each circular buffer area with a radius of $1 \mathrm{~m}$ around the bamboo sticks for the farmer's field, respectively. The plots of the field experiment were previously clipped with an inner buffer of $60 \mathrm{~cm}$ for preventing border effects. Additionally, the manually measured heights were averaged for each plot $(n=54)$ or area around the bamboo sticks $(n=24)$. These values were compared with the mean plant heights derived from the CSMs of the same respective spatial feature for evaluating and validating the laser scanning results.

\subsection{Biomass Regression Model}

As mentioned before, the problem of the nondestructive estimation of crop biomass on field level is not solved yet, while indirect approaches successfully used plant height as predictor. In order to investigate the correlation between plant height and biomass of rice plants, a regression model was derived from the results of the field experiment. The transferability of the model to the farmer's conventionally managed field was validated by comparing the simulated and measured biomass. As mentioned, different rice varieties were cultivated on both test sites. The two rice varieties from the field experiment were combined in the regression model to ensure an adequate number of measured values $(n=90)$ and attain a reasonable mean value for the transfer to the 
farmer's field. The combination of the different treatments covers the influence of the varying amount of used fertilizer. Previously, three test models were established for testing the general concept. For each test model, the regression equation from two repetitions of the field experiment were used for simulating the biomass of the third repetition.

The workflow can be structured in five steps:

1. Generation of the test models, considering only the field experiment.

2. Evaluation of the correlation between all CSM-derived plant height and destructive biomass sampling for the field experiment and derivation of the regression model.

3. Application of the regression model for simulating the biomass on the farmer's field based on the CSM-derived plant height.

4. Evaluation of the simulated and destructively measured biomass of the farmer's field.

5. Validation of the regression model using the additional independent measurements of biomass of the overall farmer's field.

\section{Results}

\subsection{Spatial Analysis}

After the described data processing of the captured TLS point clouds, the CSMs for each date and both sites were generated and the plant heights were calculated pixel-wise. Thus, the following spatial and temporal patterns and variations within one CSM and between different CSMs can be obtained. As an example, Fig. 8 shows 12 maps of plant height derived from the CSMs. For all three TLS campaign dates, the maps of two repetitions of the same fertilizer treatment for Kongyu 131 (plots 162 and 163) and Longjing 21 (plots 261 and 262) are shown.

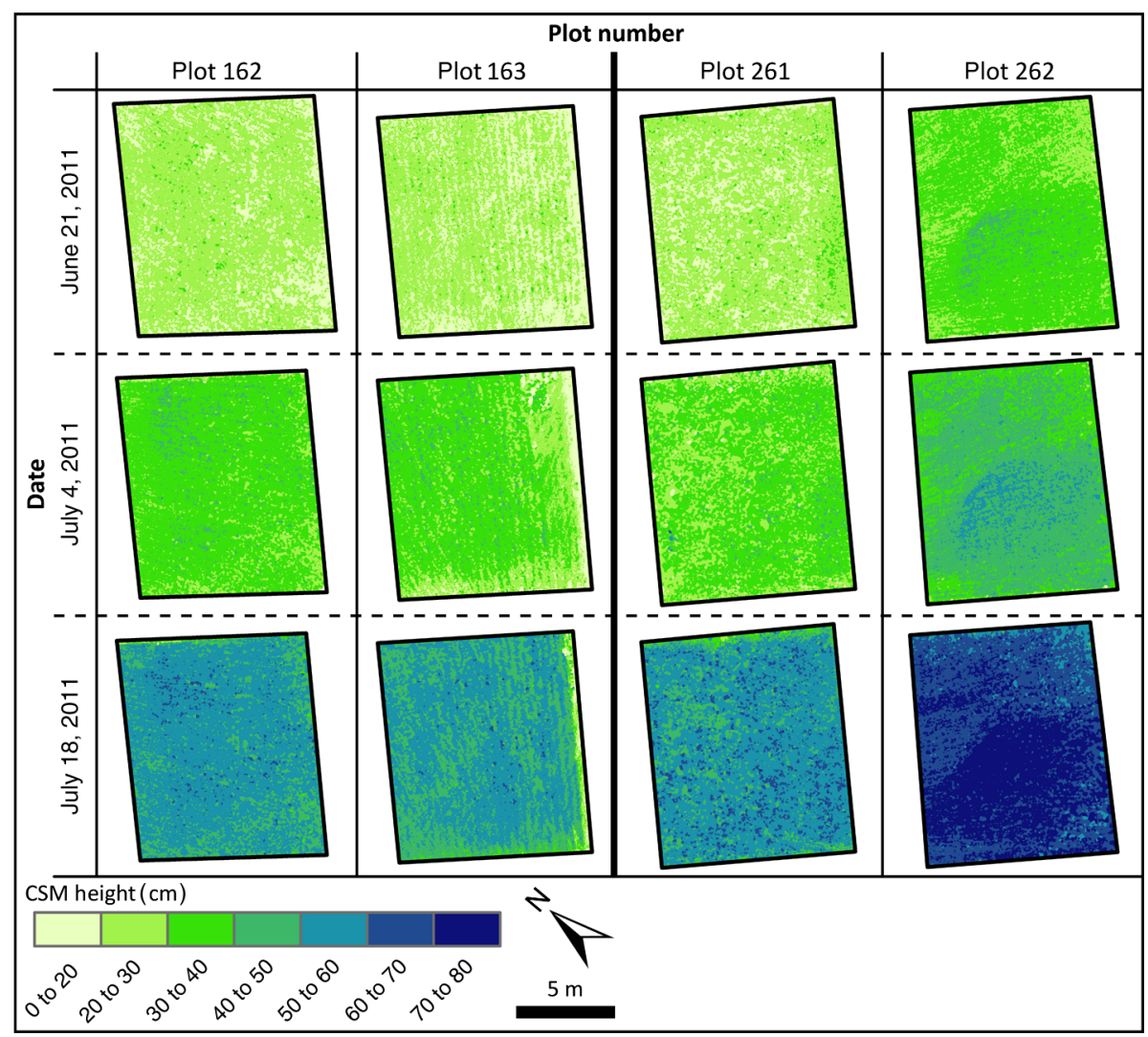

Fig. 8 CSM-derived maps of plant height for four selected plots of the field experiment (left: Kongyu 131; right: Longjing 21, marked in Fig. 3). 


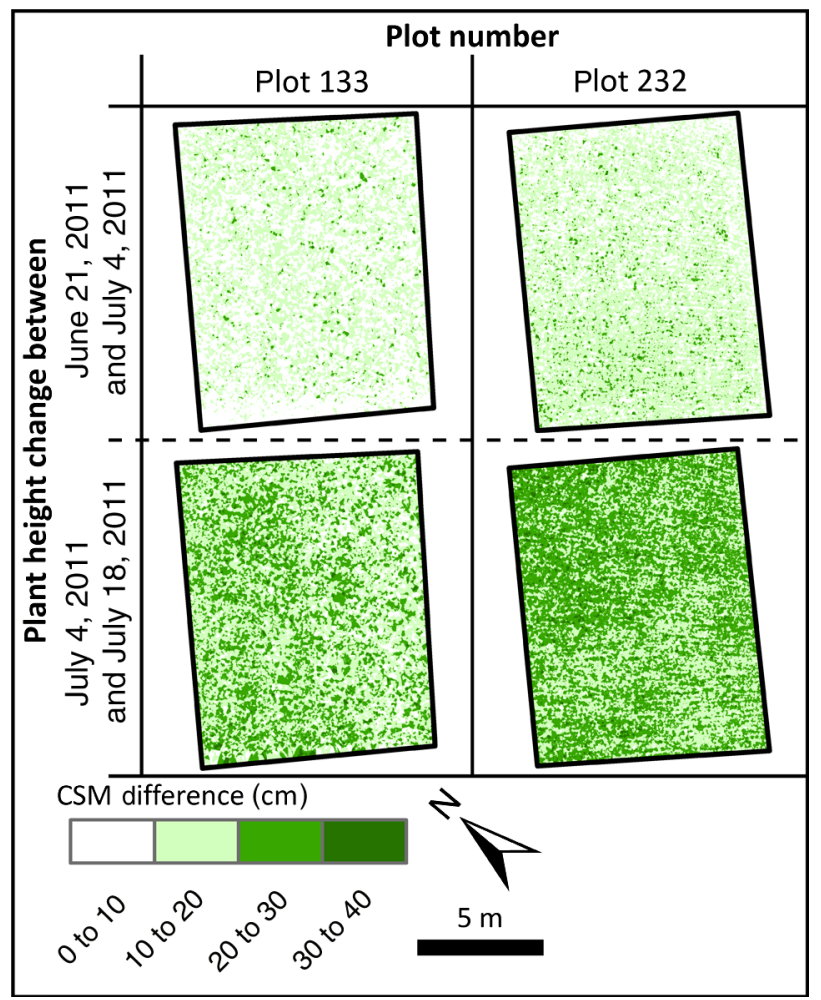

Fig. 9 Maps of plant growth for two selected plots field of the field experiment, derived from the difference between two consecutive CSMs (left: Kongyu 131; right: Longjing 21, marked in Fig. 3).

All field experiment plots and the whole farmer's field are represented in the way it is shown in Fig. 8.

The linear structure of the rice plant rows within the plots is detectable at the first campaign but disappears later due to plant development. Regarding the field experiment, slight differences between the rice varieties can be identified. The latter difference is captured by examining the mean plant height per plot, which shows higher values for Longjing 21 . The averaged difference between the varieties increases over the time $(4,5$, and $10 \mathrm{~cm})$. In addition, the plant growth is observable, which is determined as height difference between consecutive CSMs and visualized as maps of plant growth. In Fig. 9, maps of Kongyu 131 (plot 133) and Longjing 21 (plot 232) for both time intervals are shown as an example. In both intervals, the growth patterns are almost homogeneous within the plots for both varieties. According to the increasing height difference between the varieties over the time, the growth values are higher for Longjing 21.

The mean plant heights calculated from the CSMs were validated against the averaged manually measured plant heights for each plot or area around the bamboo sticks for verifying the results. Figure 10 shows the difference between these values for the first campaign on the field experiment. The variance is quite small. About $40 \%$ of the plots show a difference of $<2 \mathrm{~cm}$, further $45 \%$ differ by 2 to $5 \mathrm{~cm}$, and just $15 \%$ show a higher error, reaching the maximum at about $10 \mathrm{~cm}$. The mean difference between all CSM-derived and manually measured plant heights is about $3 \mathrm{~cm}$ for the plots of the field experiment and about $9 \mathrm{~cm}$ for the buffer areas around the bamboo sticks of the intensively investigated units of the farmer's field, each with a standard deviation of about $5 \mathrm{~cm}$.

\subsection{Statistical Analysis}

The CSM-derived and the manually measured plant heights, averaged for each plot or buffer area, were used for executing correlation and regression analyses. Common statistical values are shown in Table 3. For each campaign and both sites, the mean heights are quite similar. The differences between the mean CSM-derived and manually measured plant heights are 
Tilly et al.: Multitemporal crop surface models: accurate plant height measurement and biomass estimation...

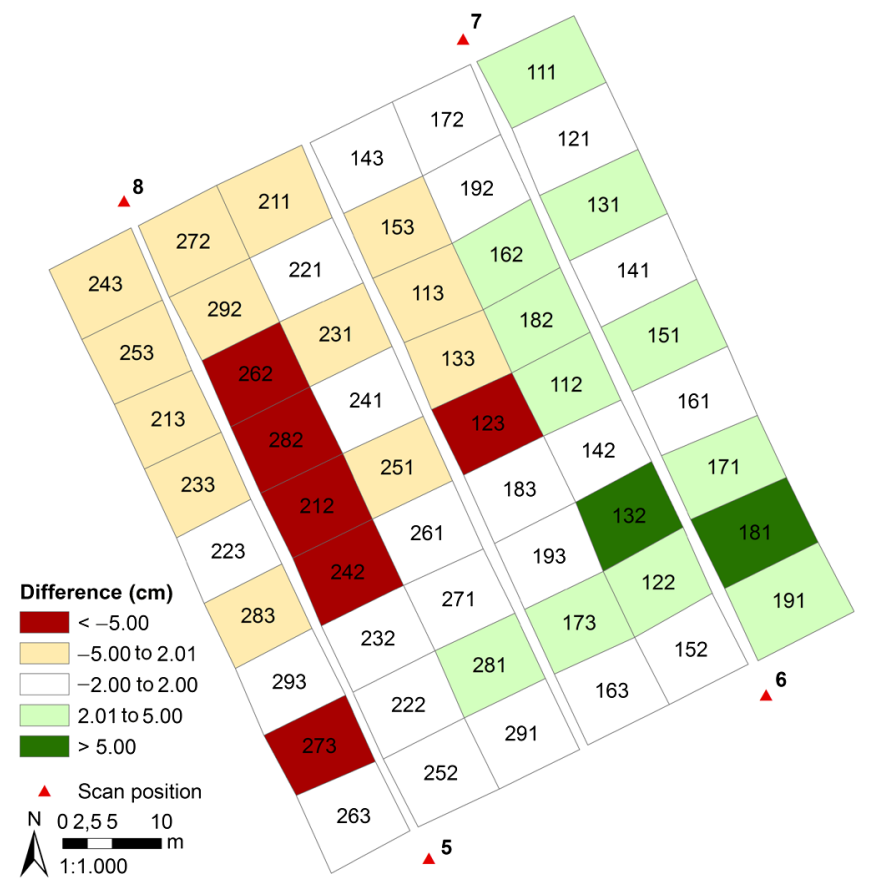

Fig. 10 Difference between the averaged manually measured plant heights and the CSM-derived mean plant heights for each plot for the first campaign of the field experiment.

about $3 \mathrm{~cm}$ for the field experiment and $9 \mathrm{~cm}$ for the farmer's field. The standard deviation within each campaign is about $5 \mathrm{~cm}$ for both sites. All minimum values are lower for the CSM-derived mean plant heights, whereas the maximum values are more similar. All values and the resulting regression lines for both fields are shown in Fig. 11. The correlation coefficients are very high for each field (both $R^{2}=0.91$ ).

\subsection{Biomass Regression Model}

As mentioned earlier, for destructive biomass sampling on the field experiment, only treatments 1 to 5 were considered, with the main different levels of $\mathrm{N}$ fertilization. Hence, the number of samples and accordingly the averaged plant height values differ from the comparison of the height measurement methods (Table 3). In the intensively investigated units of the farmer's

Table 3 Mean CSM-derived and manually measured plant heights for both fields.

\begin{tabular}{|c|c|c|c|c|c|c|c|c|c|}
\hline \multirow[b]{2}{*}{ Date } & \multirow[b]{2}{*}{$N$} & \multicolumn{4}{|c|}{ Plant height from CSM $(\mathrm{cm})$} & \multicolumn{4}{|c|}{ Measured plant height $(\mathrm{cm})$} \\
\hline & & $\bar{x}$ & $s$ & Min & Max & $\bar{x}$ & $s$ & Min & Max \\
\hline \multicolumn{10}{|c|}{ Field experiment } \\
\hline June 21, 2011 & 54 & 24.84 & 3.63 & 17.90 & 32.99 & 24.37 & 2.06 & 19.13 & 28.88 \\
\hline July 4, 2011 & 54 & 34.62 & 4.36 & 24.59 & 42.71 & 37.94 & 2.42 & 32.38 & 44.13 \\
\hline July 18, 2011 & 54 & 55.38 & 7.22 & 44.28 & 70.30 & 63.56 & 4.25 & 53.10 & 70.70 \\
\hline \multicolumn{10}{|l|}{ Farmer's field } \\
\hline June 22, 2011 & 24 & 20.80 & 4.82 & 13.39 & 31.44 & 29.18 & 2.87 & 23.25 & 37.00 \\
\hline June 5, 2011 & 24 & 34.09 & 4.52 & 27.13 & 44.60 & 40.62 & 1.93 & 38.25 & 43.75 \\
\hline July 19, 2011 & 24 & 59.49 & 4.87 & 51.79 & 72.58 & 71.64 & 2.63 & 67.50 & 76.50 \\
\hline
\end{tabular}




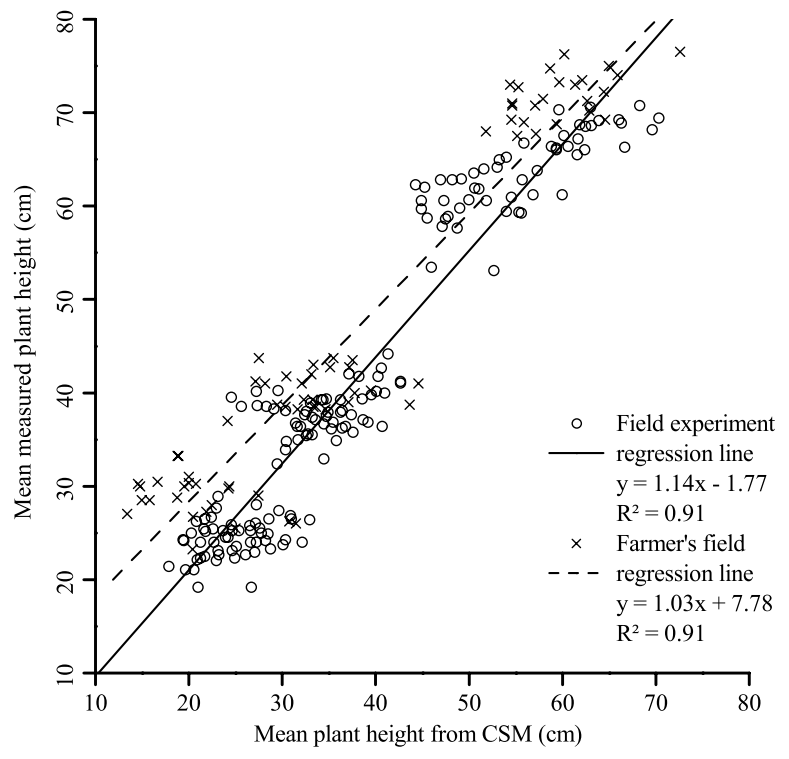

Fig. 11 Regression of the mean CSM-derived and manually measured plant heights for the field experiment $(n=162)$ and the intensively investigated units on the farmer's field $(n=72)$.

field, the biomass was taken around all bamboo sticks. For each campaign, the mean value, standard deviation, minimum, and maximum were calculated for the plant height and dry biomass (Table 4). The mean plant heights of each campaign are similar for the field experiment and the farmer's field, with a difference of $<5 \mathrm{~cm}$. In contrast, the averaged dry biomass values of the field experiment are $20 \%$ to $30 \%$ lower than the values of the farmer's field at the second and third campaign.

The general concept of the biomass regression model was validated with three test models. Therefore, the regression equation achieved from two repetitions of the field experiment was used for calculating the biomass of the respective third repetition. The mean deviations of the simulated values from the actual measured values are 3\%, 16\%, and $19 \%$.

Considering now both fields, the relationship between the mean plant height and dry biomass is visualized in a scatter plot (Fig. 12). The lower biomass values of the field experiment are also visible, but the linear correlation is similar for both sites. The regression equation from the field experiment $(y=11.06 x-224.18)$ was used for deriving the biomass regression model.

Table 4 Mean CSM-derived plant heights and biomass values.

\begin{tabular}{|c|c|c|c|c|c|c|c|c|c|}
\hline \multirow[b]{2}{*}{ Date } & \multirow[b]{2}{*}{$n$} & \multicolumn{4}{|c|}{ Plant height from CSM $(\mathrm{cm})$} & \multicolumn{4}{|c|}{ Dry biomass $\left(\mathrm{g} / \mathrm{m}^{2}\right)^{\mathrm{a}}$} \\
\hline & & $\bar{x}$ & $s$ & Min & Max & $\bar{x}$ & $s$ & Min & Max \\
\hline \multicolumn{10}{|c|}{ Field experiment } \\
\hline June 21, 2011 & 30 & 24.93 & 2.85 & 20.59 & 30.33 & 59.51 & 18.86 & 24.04 & 100.70 \\
\hline July 4, 2011 & 30 & 33.80 & 3.74 & 27.25 & 40.75 & 131.72 & 30.03 & 66.71 & 199.41 \\
\hline July 18, 2011 & 30 & 56.69 & 5.49 & 44.91 & 63.03 & 422.27 & 80.90 & 274.74 & 599.53 \\
\hline \multicolumn{10}{|l|}{ Farmer's field } \\
\hline June 22, 2011 & 24 & 20.80 & 4.82 & 13.39 & 31.44 & 57.58 & 13.02 & 25.64 & 80.01 \\
\hline July 5, 2011 & 24 & 34.09 & 4.52 & 27.13 & 44.60 & 217.43 & 29.44 & 146.54 & 278.12 \\
\hline July 19, 2011 & 24 & 59.49 & 4.87 & 51.79 & 72.58 & 589.71 & 73.01 & 482.33 & 723.32 \\
\hline
\end{tabular}

${ }^{a}$ Values for the field experiment are interpolated. 
Tilly et al.: Multitemporal crop surface models: accurate plant height measurement and biomass estimation...

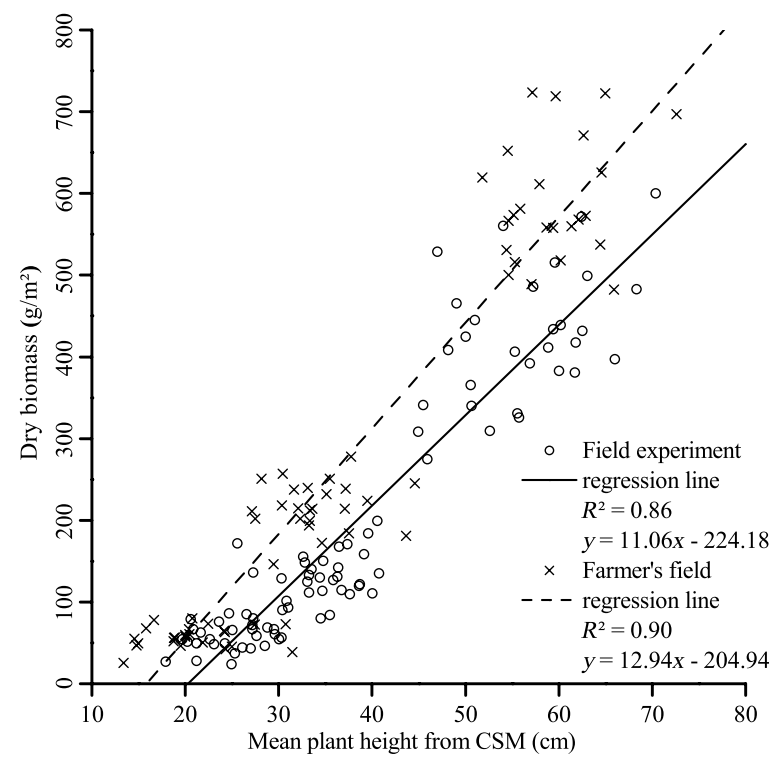

Fig. 12 Regression of the mean CSM-derived plant height and dry biomass for the field experiment $(n=90)$ and the intensively investigated units on the farmer's field $(n=72)$.

Following, the biomass on the intensively investigated units of the farmer's field was estimated with the model, based on the CSM-derived plant heights. Figure 13 shows the simulated biomass, with once the standard deviation calculated for each campaign, and the actual measured values. The reliability of the established model is supported by the strong correlation between simulated and measured values $\left(R^{2}=0.90\right)$. The mean difference between the values is $90 \mathrm{~g} / \mathrm{m}^{2}$ (about $\frac{1}{4}$ of the mean measured dry biomass), with a standard deviation of $80 \mathrm{~g} / \mathrm{m}^{2}$.

The regression model was validated and the transferability to any point in time within the observation period was checked with the biomass measurements on the overall farmer's field. As the increase in plant height over the time is almost linear in the observation period, a linear function achieved from all CSM-derived plant height values was used for interpolating the plant heights for the 26th of June. The theoretical biomass was estimated with the regression

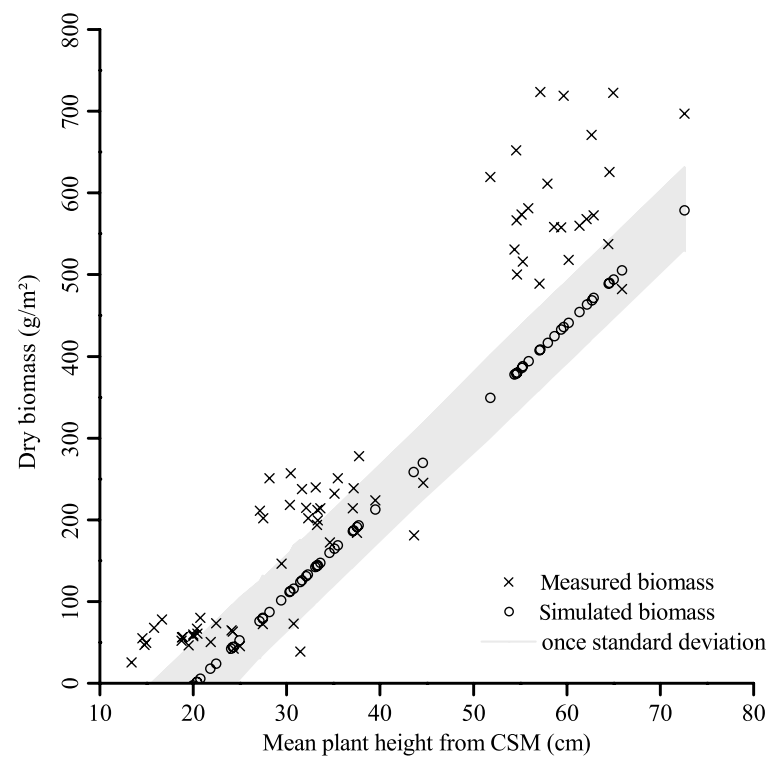

Fig. 13 Theoretical biomass simulated with regression model and the measured values for the intensively investigated units on the farmer's field (each: $n=72$ ). 
Table 5 Biomass values for the overall farmer's field.

\begin{tabular}{lccccc}
\hline \hline & & \multicolumn{4}{c}{ Dry biomass $\left(\mathrm{g} / \mathrm{m}^{2}\right)$} \\
\cline { 3 - 5 } & $n$ & $\bar{x}$ & $s$ & Min & Max \\
\hline Simulated values & 28 & 64.25 & 30.51 & 16.04 & 128.68 \\
Measured values & 28 & 79.32 & 15.91 & 50.02 & 113.23 \\
Difference between related samples & 28 & 15.07 & 36.36 & 0.50 & 84.88 \\
\hline \hline
\end{tabular}

model and compared to the measured values. Table 5 gives the basic statistics for the simulated and measured biomass values. The mean difference between both values is $15 \mathrm{~g} / \mathrm{m}^{2}$ (about $20 \%$ of the mean measured dry biomass), with a standard deviation of $36 \mathrm{~g} / \mathrm{m}^{2}$.

\section{Discussion}

Generally, the data acquisition with the laser scanner in the field worked very well. The lightweight build-up of the Riegl VZ-1000 is quite helpful. Nevertheless, problems occur from noise in the point clouds, due to wind, rain, insects, or small particles in the air, reflections on water, and other effects. These issues for TLS applications in agriculture are also reported in Refs. 42 and 50. The time-of-flight scanner, used in this study, reduces the noise already by the high measuring speed. Further improvements are possible with the software filter options in RiSCAN Pro. Earlier studies with a comparable setup ${ }^{51}$ already showed the usability of this method, but further improvement is still desirable. Approaches for automatic corrections of internal errors focus on systematic error models and self-calibration methods. ${ }^{62}$

Further possibilities are the investigation of intensity values, which can be used for establishing a filtering scheme of separating laser returns on canopy from ground returns ${ }^{63}$ or for detecting single plants, ${ }^{47,48}$ as already stated. In addition, the application of full-waveform analysis for identifying vegetation in point clouds is commonly known from airborne laser scanning (ALS) ${ }^{33,64}$ New TLS systems are also capable for retrieving the full-waveform of the reflected signal and their role for the detection of vegetation gets increasingly important. ${ }^{65,66}$

A major advantage of the terrestrial laser scanner is the easily achievable and fast data acquisition of a whole field. Besides that, a higher spatial resolution and higher point density than achievable with $\operatorname{ALS}^{67}$ are reachable, which enables an accurate differentiation between the plots and allows the identification of small objects, like the bamboo sticks used on the farmer's field. Nevertheless, the approach leaves room for improvement, for example, enhancing the evenness of the point cloud distribution. Recent developments in mobile laser scanning (MLS) brought up promising solutions ${ }^{68}$ In general, MLS comprises all measurement systems with two-dimensional profiling scanners, attached to a moving ground vehicle for achieving an areal coverage. This method was already used in several studies for crop monitoring and detection purposes. ${ }^{42,46,69,70}$ For the limited access on the small dikes of the paddy rice fields, the new Akhka MLS system, ${ }^{70}$ where the laser scanner is attached to a backpack, has a promising potential.

In the literature, ${ }^{71}$ the problem of overestimating the height of reflection points depending on the scanning angles is examined. In this study, the point clouds of all scan positions from one campaign date were merged for achieving an evenly distributed coverage of the field and a scheme for filtering the maximum points was used for detecting the crop surface. However, referring to Ref. 71, the influence of the scanning angles has to be taken into account for further studies, in particular for MLS systems.

One source of error for validating the CSM measurements with the manual measurements is the height variances within the observed spatial unit. Considering the manual measurements, such within-field variations are already detectable. As mentioned, on the field experiment, the heights of 8 to 10 hills per plot were measured. The mean standard deviations within those measurements are already $4,4.5$, and $5.5 \mathrm{~cm}$ for the respective three campaigns, 
respectively. Regarding the CSM-derived plant heights, many more measuring points exist, with one height value for each pixel. Hence, the whole area of the plot is captured, including lower parts. With respect to those within-field variations and differences between the measuring techniques, the mean difference of $3 \mathrm{~cm}$ between averaged CSM-derived and manually measured plant heights is reasonable (Table 3). Considering Fig. 10, the few samples (15\%) with differences between 5 and $10 \mathrm{~cm}$ can probably be related to these uncertainties and variations. Moreover, for the first campaign, a difference between the rice varieties on the field experiment might be detectable. Although for Kongyu 131, mostly the manually measured plant heights are higher than the CSM-derived values (positive difference), contrasting patterns, resulting in negative differences, are observable for Longjing 21 . However, those tendencies are not observable for the other campaigns.

Regarding the farmer's field, similar patterns are clearly visible. In the intensively investigated units, only the heights of four hills around each bamboo stick were manually measured, which assumably leads to the lower standard deviation ( $3,2.5$, and $4 \mathrm{~cm}$ for the three campaigns). However, the difference between the averaged manual measurements and CSM-derived plant heights is larger $(9 \mathrm{~cm})$, as the manual measurements covered only small parts of the area, mostly representing the highest parts of the crop surface. In contrast, the scanner captures the whole area, including lower parts, resulting in a high number of measuring points. Thus, the mean values of the pixel-wise stored CSM-derived plant heights per circular buffer area are lower, which explains the overall lower minimum values for the CSM-derived plant heights (Table 3).

In summary, the manual measurements with strong correlations to the averaged CSM-derived values validate the accuracy of the TLS results. Due to the very different numbers of samplings per plot, only averaged values can be compared. As mentioned, the heights less than 10 hills per each spatial unit were manually measured. In contrast, the resolution of $1 \mathrm{~cm}$ of the CSMs results in a huge number of measuring points for each spatial unit (about 500,000 points for each plot and 30,000 point for each buffer area on the field experiment and farmer's field, respectively). Through this high resolution, also smaller hills and lower parts of the plants are captured, which decrease the minimum values and increase the standard deviation (Table 3). Nevertheless, the comparable mean values of the measurement methods, with deviations of $2 \%$ to $15 \%$ for the field experiment and $15 \%$ to $30 \%$ for the farmer's field, lead to regressions with high correlation coefficients (Fig. 11). The much higher spatial resolution and the acquisition of the whole area are the main benefits of the TLS approach and required for accurate crop monitoring in the context of precision agriculture. ${ }^{3}$ However, the precision of the CSMs can hardly be validated with the manual measurements. Other studies show that TLS measurements are supposed to be precise. $^{40,48,50}$ The high accuracy and precision of the Riegl VZ-1000 are validated with the performance test by the manufacturer. ${ }^{56}$ Moreover, the TLS approach immensely reduces the human error factor, which cannot be neglected for the manual measurements.

Although the TLS data acquisition worked well, some uncertainties remain. Due to the field management and construction, it was not possible to obtain a DEM from the AOI without any vegetation and water. Thus, the DEM had to be estimated from the point clouds of the respective first campaigns, containing already small plants. The low water height in the field of about $4 \mathrm{~cm}$ and the remaining ground at the edges and around the hills enabled this approach. Nevertheless, the high correlation coefficients and small differences between the CSM-derived and the manually measured plant heights justify this assumption.

For paddy rice fields, border effects have to be regarded, resulting in differences between internal and external rice plants in a plot. ${ }^{72}$ The executed application of a buffer, to cut off the outmost rows, is suitable for avoiding border effects. However, uncertainties still remain, for example, about the appropriate size. The compiled CSMs show the applicability of the presented method of calculating crop heights in rice fields with a high spatial resolution (up to $1 \mathrm{~cm}$, Fig. 8) and accuracy. In contrast, spaceborne data, which are commonly used for rice field mapping reach a spatial resolution not higher than $1 \mathrm{~m}^{.19-21}$ The results demonstrate the potential of TLS for accurate in situ measurement on paddy rice fields, which could also be a validation for spaceborne remote sensing data. Furthermore, the transferability of virtual modeled rice plants to field level can be validated. ${ }^{24,25}$

Reconsidering the model presented in Ref. 30, the CSM-derived plant heights can be used for predicting yield potential for rice. In this context, the mentioned influence of border effects is a 
general problem for estimating rice yield. ${ }^{72}$ The very high resolution of the TLS-derived CSMs might be useful for quantifying this effect and estimate differences between internal and external rows.

The strong correlation between plant height and biomass $\left(R^{2}=0.86\right)$ enabled the derivation of the regression model for estimating the actual biomass of rice plants. Strong correlations between plant height and biomass were also reported in Ref. 42 for different crops. The transferability of the established model to a larger-scale farmer's field was demonstrated. Differences between the theoretical biomass, simulated with the regression model, and the actual measured values can be related to the mentioned differences between the investigated fields. The BBCHvalues (Table 2) show that all varieties were almost in the same phenological stage, but differences in plant height and biomass are measurable. The biomass values of the field experiment are up to a third smaller than the values of the farmer's field (Table 4). Hence, the simulated values differ from the measured values with a mean difference of about $25 \%$ of the mean measured dry biomass. Regarding the general concept of the biomass regression model, better simulations were possible with the established test models, where only the rice varieties on the field experiment were used. As mentioned, the mean differences between the simulated and measured values are $3 \%, 16 \%$, and $19 \%$. Further investigations are required, regarding the differences and whether they are caused by the different rice varieties or fertilizer treatments. Other influencing factors might be different soil conditions or lower human impact and larger plot size on the farmer's field. In Ref. 49, the authors achieved good results for estimating the biomass of rice plants based on the vertical plant area density, measured with a portable scanner in combination with a mirror. However, the setup might be less practical for the application on larger-scale fields.

The estimated biomass values may be used for improving NNI calculations and N management strategies, ${ }^{29}$ as the actual biomass is a key factor for the evaluation of the field status and management decisions. Hence, the claimed improvement of the relationship between input and output $^{3}$ can be realized to reduce over-fertilization and shrink the gap between potential and current yield.

Accurate captured rice fields can also be used for modeling purposes. In Ref. 73, a model is presented for rating damages from rice field rats and corresponding yield losses. The extent of damages was assumed, based on the experiences of the involved farmers. Damages can also be caused by other sources like storms, rain, or plant diseases. Measurements with TLS could be more accurate for predicting the damaged biomass. Furthermore, crop simulation models can be used for estimating the potential and current yield. ${ }^{2}$ Therefore, the CSM-derived height and estimated biomass values can be used as model input or validation data.

For the presented approach, the improvement of the temporal interpolation method for the plant height values to any point in time is desirable. In this study, the CSM-derived mean plant heights were interpolated. Better results might be reached with a pixel-wise raster interpolation and subsequent averaging of the interpolated pixel values for estimating the mean plant height for a given day in the investigation period.

\section{Conclusion}

The presented method of producing multitemporal CSMs based on TLS measurements is applicable for nondestructive capturing and monitoring of rice growth. The very high spatial resolution and accuracy of the point clouds are the most outstanding features of TLS. Regarding the varying performance of plant growth on the field experiment, further studies might focus on the different rice varieties and fertilizer treatments. Therefore, similar datasets of the same field experiment of consecutive years should be considered.

The Riegl VZ-1000 is comparatively expensive. However, for this study, a TLS system, known for high precision and accuracy, was required to avoid system-based errors. Recent developments brought up cost-effective system, like the Velodyne HDL-64E LiDAR sensor. ${ }^{74}$ Such systems should be regarded for realizing the practical implementation and application for farmers. Further, more cost-effective approaches are conceivable with MLS systems like the ibeo ALASCA XT. ${ }^{71}$ 
In the context of precision agriculture, biomass is a key factor for management decisions. As mentioned, to this day, it is impossible to directly measure the actual crop biomass nondestructively. Hence, remote and proximal sensing measurements for estimating actual values in-season are required. The results show the strong correlation between plant height and biomass $\left(R^{2}=0.86 ; R^{2}=0.90\right)$ for the analyzed time of the growing period. The transferability of the established biomass regression model based on plant height measurements from a smallscale field experiment to a larger-scale farmer's conventionally managed field was supported. Differences between the two sites, e.g., rice varieties, plot size, and fertilizer treatment, lead to differences between the simulated and measured values, but the strong correlation $\left(R^{2}=0.90\right)$ demonstrates the coherence of the results. Furthermore, the independent biomass dataset from the overall field was used for validating the temporal transferability. In further studies, the transferability to other farmers' conventionally managed fields has to be checked. The accuracy of the simulated biomass shows the suitability of the established model and reveals the presented method as a promising approach for the nondestructive in-season estimation of biomass within-field resolution in paddy rice.

\section{Acknowledgments}

This work was financially supported by the International Bureau of the German Federal Ministry of Education and Research (BMBF, Project No. 01DO12013) and the German Research Foundation (DFG, Project No. BA 2062/8-1). We gratefully thank the Qixing Research and Development Centre, the Jiansanjiang Agricultural Research Station (both located in Heilongjiang Province, China) and Five Star Electronic Technologies (Beijing, China) for good cooperation. Furthermore, we like to thank RIEGL LMS GmbH (Horn, Austria) for continuous support. We thank the anonymous reviewers for their valuable comments, which clearly enhanced the paper.

\section{References}

1. Food and Agriculture Organization (FAO), "FAOSTAT," http://faostat.fao.org/ (1 February 2014).

2. J. Van Wart et al., "Estimating crop yield potential at regional to national scales," Field Crops Res. 143(1), 34-43 (2013), http://dx.doi.org/10.1016/j.fcr.2012.11.018.

3. D. J. Mulla, "Twenty five years of remote sensing in precision agriculture: key advances and remaining knowledge gaps," Biosyst. Eng. 114(4), 358-371 (2013), http://dx.doi.org/10 .1016/j.biosystemseng.2012.08.009.

4. D. A. Ntanos and S. D. Koutroubas, "Dry matter and N accumulation and translocation for Indica and Japonica rice under Mediterranean conditions," Field Crops Res. 74(1), 93-101 (2002), http://dx.doi.org/10.1016/S0378-4290(01)00203-9.

5. Y. Miao, B. Stewart, and F. Zhang, "Long-term experiments for sustainable nutrient management in China. A review," Agron. Sustainable Dev. 31(2), 397-414 (2011), http://dx.doi .org/10.1051/agro/2010034.

6. M. Roelcke et al., "Recent trends and recommendations for nitrogen fertilization in intensive agriculture in eastern China," Pedosphere 14(4), 449-460 (2004).

7. B. Mistele and U. Schmidhalter, "Estimating the nitrogen nutrition index using spectral canopy reflectance measurements,” Eur. J. Agron. 29(4), 184-190 (2008), http://dx.doi .org/10.1016/j.eja.2008.05.007.

8. G. Lemaire et al., "Developmental changes in shoot $\mathrm{N}$ dynamics of lucerne (Medicago sativa L.) in relation to leaf growth dynamics as a function of plant density and hierarchical position within the canopy," J. Exp. Bot. 56(413), 935-943 (2005), http://dx.doi.org/10 .1093/jxb/eri084.

9. F. Devienne-Barret et al., "Integrated control of nitrate uptake by crop growth rate and soil nitrate availability under field conditions," Ann. Bot. 86(5), 995-1005 (2000), http://dx.doi .org/10.1006/anbo.2000.1264.

10. A. Elia and G. Conversa, "Agronomic and physiological responses of a tomato crop to nitrogen input," Eur. J. Agron. 40, 64-74 (2012), http://dx.doi.org/10.1016/j.eja.2012.02.001. 
Tilly et al.: Multitemporal crop surface models: accurate plant height measurement and biomass estimation...

11. G. Lemaire, M. H. Jeuffroy, and F. Gastal, "Diagnosis tool for plant and crop N status in vegetative stage. Theory and practices for crop N management," Eur. J. Agron. 28, 614-624 (2008), http://dx.doi.org/10.1016/j.eja.2008.01.005.

12. D. J. Greenwood et al., "Growth rate and \% $\mathrm{N}$ of field grown crops: theory and experiments," Ann. Bot. 67(2), 181-190 (1991).

13. J. Huang et al., "Determination of optimal nitrogen rate for rice varieties using a chlorophyll meter," Field Crops Res. 105(1-2), 70-80 (2008), http://dx.doi.org/10.1016/j.fcr.2007.07 .006 .

14. S. Peng et al., "Increased N-use efficiency using a chlorophyll meter on high-yielding irrigated rice," Field Crops Res. 47(2-3), 243-252 (1996), http://dx.doi.org/10.1016/03784290(96)00018-4.

15. K. Yu et al., "Remotely detecting canopy nitrogen concentration and uptake of paddy rice in the Northeast China Plain," ISPRS J. Photogramm. Remote Sens. 78, 102-115 (2013), http://dx.doi.org/10.1016/j.isprsjprs.2013.01.008.

16. D. Stroppiana et al., "Plant nitrogen concentration in paddy rice from field canopy hyperspectral radiometry," Field Crops Res. 111(1-2), 119-129 (2009), http://dx.doi.org/10 .1016/j.fcr.2008.11.004.

17. Q-X. Yi et al., "Monitoring rice nitrogen status using hyperspectral reflectance and artificial neural network," Environ. Sci. Technol. 41(19), 6770-6775 (2007), http://dx.doi.org/10 .1021/es070144e.

18. C. Ryu, M. Suguri, and M. Umeda, "Multivariate analysis of nitrogen content for rice at the heading stage using reflectance of airborne hyperspectral remote sensing," Field Crops Res. 122(3), 214-224 (2011), http://dx.doi.org/10.1016/j.fcr.2011.03.013.

19. W. Koppe et al., "Rice monitoring with multi-temporal and dual-polarimetric TerraSAR-X data," Int. J. Appl. Earth Obs. Geoinf. 21, 568-576 (2013), http://dx.doi.org/10.1016/j.jag 2012.07.016.

20. J. M. Lopez-Sanchez, J. D. Ballester-Berman, and I. Hainsek, "First results of rice monitoring practices in Spain by means of time series of TerraSAR-X dual-pol images," IEEE J. Sel. Top. Appl. Earth Obs. Remote Sens. 4(2), 412-422 (2011), http://dx.doi.org/10.1109/ JSTARS.2010.2047634.

21. F. Ribbes and T. Le-Toan, "Rice field mapping and monitoring with RADARSAT data," Int. J. Remote Sens. 20 (4), 745-765 (1999), http://dx.doi.org/10.1080/014311699213172.

22. W. Li, H. Li, and L. Zhao, "Estimating rice yield by HJ-1A satellite images," Rice Sci. 18(2), 142-147 (2011), http://dx.doi.org/10.1016/S1672-6308(11)60020-6.

23. X. H. Yang et al., "Estimating biophysical parameters of rice with remote sensing data using support vector machines," Sci. China Life Sci. 54 (3), 272-281 (2011), http://dx.doi.org/10 .1007/s11427-011-4135-4.

24. W. Ding et al., "Realistic simulation of rice plant," Rice Sci. 18(3), 224-230 (2011), http:// dx.doi.org/10.1016/S1672-6308(11)60031-0.

25. T. Watanabe et al., "Rice morphogenesis and plant architecture: measurement, specification and the reconstruction of structural development by 3D architectural modelling," Ann. Bot. 95(7), 1131-1143 (2005), http://dx.doi.org/10.1093/aob/mci136.

26. D. Casanova, G. F. Epema, and J. Goudriaan, "Monitoring rice reflectance at field level for estimating biomass and LAI," Field Crops Res. 55(1-2), 83-92 (1998), http://dx.doi.org/10 .1016/S0378-4290(97)00064-6.

27. M. L. Gnyp et al., "Analysis of crop reflectance for estimating biomass in rice canopy at different phenological stages," Photogramm. Fernerkundung Geoinf. 2013(4), 351-365 (2013), http://dx.doi.org/10.1127/1432-8364/2013/0182.

28. H. Aasen et al., "Automated hyperspectral vegetation index retrieval from multiple correlation matrices with HyperCor," Photogramm. Eng. Remote Sens., accepted for publication.

29. Y. Yao et al., "Active canopy sensor-based precision N management strategy for rice," Agron. Sustainable Dev. 32(4), 925-933 (2012), http://dx.doi.org/10.1007/s13593-0120094-9.

30. R. Confalonieri, "A model for simulating the height of rice plants," Eur. J. Agron. 34(1), 20-25 (2011), http://dx.doi.org/10.1016/j.eja.2010.09.003. 
Tilly et al.: Multitemporal crop surface models: accurate plant height measurement and biomass estimation...

31. M. van Leeuwen et al., "Assessment of standing wood and fiber quality using ground and airborne laser scanning: a review," Forest Ecol. Manage. 261(9), 1467-1478 (2011), http:// dx.doi.org/10.1016/j.foreco.2011.01.032.

32. M. A. Lefsky et al., "Lidar remote sensing for ecosystem studies," Bioscience 52(1), 19-30 (2002), http://dx.doi.org/10.1641/0006-3568(2002)052[0019:LRSFES]2.0.CO;2.

33. J. Hyyppä et al., "Review of methods of small footprint airborne laser scanning for extracting forest inventory data in boreal forests," Int. J. Remote Sens. 29 (5), 1339 1366 (2008), http://dx.doi.org/10.1080/01431160701736489.

34. K. Omasa, F. Hosoi, and A. Konishi, "3D lidar imaging for detecting and understanding plant responses and canopy structure," J. Exp. Bot. 58(4), 881-898 (2007), http://dx.doi.org/ $10.1093 / \mathrm{jxb} / \mathrm{erl} 142$.

35. J. G. Henning and P. J. Radtke, "Ground-based laser imaging for assessing three-dimensional forest canopy structure," Photogramm. Eng. Remote Sens. 72(12), 1349-1358 (2006), http://dx.doi.org/10.14358/PERS.72.12.1349.

36. F. Hosoi and K. Omasa, "Voxel-based 3-D modeling of individual trees for estimating leaf area density using high-resolution portable scanning lidar," IEEE Trans. Geosci. Remote Sens. 44(12), 3610-3618 (2006), http://dx.doi.org/10.1109/TGRS.2006.881743.

37. D. van der Zande et al., "Influence of measurement set-up of ground-based LiDAR for derivation of tree structure," Agric. For. Meteorol. 141(2-4), 147-160 (2006), http://dx .doi.org/10.1016/j.agrformet.2006.09.007.

38. J. L. Lovell et al., "Using airborne and groundbased ranging lidar to measure canopy structure in Australian forests," Can. J. Remote Sens. 29(5), 607-622 (2003), http://dx.doi.org/10 $.5589 / \mathrm{m} 03-026$.

39. L. Zhang and T. E. Grift, "A LIDAR-based crop height measurement system for Miscanthus giganteus," Comput. Electron. Agric. 85, 70-76 (2012), http://dx.doi.org/10.1016/j.compag .2012.04.001.

40. K. E. Keightley and G. W. Bawden, "3D volumetric modeling of grapevine biomass using Tripod LiDAR,” Comput. Electron. Agric. 74(2), 305-312 (2010), http://dx.doi.org/10 .1016/j.compag.2010.09.005.

41. D. Ehlert, H.-J. Horn, and R. Adamek, "Measuring crop biomass density by laser triangulation," Comput. Electron. Agric. 61(2), 117-125 (2008), http://dx.doi.org/10.1016/j .compag.2007.09.013.

42. D. Ehlert, R. Adamek, and H.-J. Horn, "Laser rangefinder-based measuring of crop biomass under field conditions," Precis. Agric. 10(5), 395-408 (2009), http://dx.doi.org/10.1007/ s11119-009-9114-4.

43. F. Hosoi and K. Omasa, "Estimating vertical plant area density profile and growth parameters of a wheat canopy at different growth stages using three-dimensional portable lidar imaging," ISPRS J. Photogramm. Remote Sens. 64(2), 151-158 (2009), http://dx.doi.org/10 $.1016 /$ j.isprsjprs.2008.09.003.

44. W. Saeys et al., "Estimation of the crop density of small grains using LiDAR sensors," Biosyst. Eng. 102(1), 22-30 (2009), http://dx.doi.org/10.1016/j.biosystemseng.2008.10 .003 .

45. J. U. H. Eitel et al., "Early season remote sensing of wheat nitrogen status using a green scanning laser," Agric. For. Meteorol. 151(10), 1338-1345 (2011), http://dx.doi.org/10 .1016/j.agrformet.2011.05.015.

46. R. Gebbers, D. Ehlert, and R. Adamek, "Rapid mapping of the leaf area index in agricultural crops," Agron. J. 103(5), 1532-1541 (2011), http://dx.doi.org/10.2134/agronj2011.0201.

47. D. Hoffmeister et al., "Detektion von Wachstumsvariabilität in vier Zuckerrübensorten durch multi-temporales terrestrisches Laserscanning," in Proc. Informationstechnologie für eine nachhaltige Landbewirtschaftung, GIL-Jahrestagung, Freising, M. Clasen et al., Eds., Vol. 32, pp. 135-138, Gesellschaft für Informatik e.V., Bonn (2012).

48. B. Höfle, "Radiometric correction of terrestrial LiDAR point cloud data for individual maize plant detection," IEEE Geosci. Remote Sens. Lett. 11(1), 94-98 (2014), http://dx.doi.org/10 .1109/LGRS.2013.2247022.

49. F. Hosoi and K. Omasa, "Estimation of vertical plant area density profiles in a rice canopy at different growth stages by high-resolution portable scanning lidar with a lightweight 
Tilly et al.: Multitemporal crop surface models: accurate plant height measurement and biomass estimation...

mirror," ISPRS J. Photogramm. Remote Sens. 74, 11-19 (2012), http://dx.doi.org/10.1016/j .isprsjprs.2012.08.001.

50. J. Lumme et al., "Terrestrial laser scanning of agricultural crops," in Int. Archives of Photogrammetry, Remote Sensing and Spatial Information Sciences, J. Chen et al., Eds., Vol. 37(Part B5), pp. 563-566, International Society for Photogrammetry and Remote Sensing, Lemmer (2008).

51. D. Hoffmeister et al., "High resolution crop surface models (CSM) and crop volume models (CVM) on field level by terrestrial laser scanning," Proc. SPIE 7840, 78400E (2010), http:// dx.doi.org/10.1117/12.872315.

52. J. Gao and Y. Liu, "Climate warming and land use change in Heilongjiang Province, Northeast China," Appl. Geogr. 31(2), 476-482 (2011), http://dx.doi.org/10.1016/j .apgeog.2010.11.005.

53. D. Yihui and J. C. L. Chan, "The East Asian summer monsoon: an overview," Meteorol. Atmos. Phys. 89(1-4), 117-142 (2005), http://dx.doi.org/10.1007/s00703005-0125-z.

54. M. Domrös and P. Gongbing, The Climate of China, Springer-Verlag, Berlin (1988).

55. Q. Cao et al., "Non-destructive estimation of rice plant nitrogen status with Crop Circle multispectral active canopy sensor," Field Crops Res. 154, 133-144 (2013), http://dx .doi.org/10.1016/j.fcr.2013.08.005.

56. Riegl LMS GmbH, "Datasheet Riegl VZ-1000," 1 February 2013 (1 February 2014).

57. U. Meier, Growth Stages of Mono- and Dicotyledonous Plants, 2nd ed., Blackwell, Berlin (2001).

58. P. J. Besl and N. D. McKay, "A method for registration of 3-D shapes," IEEE Trans. Pattern Anal. Mach. Intell. 14(2), 239-256 (1992), http://dx.doi.org/10.1109/34.121791.

59. K. Johnston et al., Using ArcGIS TM Geostatistical Analyst, ESRI, USA (2001).

60. D. Hoffmeister et al., "Spatial variability detection of crop height in a single field by terrestrial laser scanning," in Precision Agriculture '13, J. V. Stafford, Ed., pp. 267-274, Wageningen Academic Publishers, Wageningen (2013), http://dx.doi.org/10.3920/97890-8686-778-3_31.

61. J. Bendig et al., "UAV-based imaging for multi-temporal, very high resolution crop surface models to monitor crop growth variability," Photogrammetrie, Fernerkundung, Geoinformation 6/2013, 551-562 (2013), http://dx.doi.org/10.5194/isprsannals-II-5-W2295-2013.

62. D. D. Lichti, "A review of geometric models and self-calibration methods for terrestrial laser scanners," Bol. Ciênc. Geod. 16(1), 3-19 (2010).

63. A. Guarnieri et al., "Retrieval of small-relief marsh morphology from terrestrial laser scanner, optimal spatial filtering, and laser return intensity," Geomorphology 113(1-2), 12-20 (2009), http://dx.doi.org/10.1016/j.geomorph.2009.06.005.

64. W. Wagner, "3D vegetation mapping using small-footprint full-waveform airborne laser scanners," Int. J. Remote Sens. 29(5), 1433-1452 (2008), http://dx.doi.org/10.1080/ 01431160701736398.

65. A. Guarnieri, F. Pirotti, and A. Vettore, "Comparison of discrete return and waveform terrestrial laser scanning for dense vegetation filtering," in Int. Archives of Photogrammetry, Remote Sensing and Spatial Information Sciences, M. Shorties et al., Eds., Vol. 39(Part B7), pp. 511-516, International Society for Photogrammetry and Remote Sensing, Melbourne (2012).

66. J. Elseberg, D. Borrmann, and A. Nüchter, "Full wave analysis in 3D laser scans for vegetation detection in urban environments," in Proc. XXIII Int. Symposium on Information, Communication and Automation Technologies, Sarajevo, Bosnia, A. Salihbegovic et al., Eds., p. 7, Institute of Electrical and Electronics Engineers, Piscataway, New Jersey (2011), on CDROM.

67. J. M. McKinion, J. L. Willers, and J. N. Jenkins, "Spatial analyses to evaluate multi-crop yield stability for a field," Comput. Electron. Agric. 70(1), 187-198 (2010), http://dx.doi .org/10.1016/j.compag.2009.10.005.

68. A. Kukko et al., "Multiplatform approach to mobile laser scanning," in International Archives of Photogrammetry, Remote Sensing and Spatial Information Sciences, M. 
Tilly et al.: Multitemporal crop surface models: accurate plant height measurement and biomass estimation...

Shortis and J. Mills, Eds., Vol. 39(Part B5), pp. 483-488, International Society for Photogrammetry and Remote Sensing, Melbourne (2012).

69. D. Andújar, "Potential of a terrestrial LiDAR-based system to characterise weed vegetation in maize crops," Comput. Electron. Agric. 92, 11-15 (2013), http://dx.doi.org/10.1016/j .compag.2012.12.012.

70. A. Kukko et al., "Multiplatform mobile laser scanning: usability and performance," Sensors 12(9), 11712-11733 (2012), http://dx.doi.org/10.3390/s120911712.

71. D. Ehlert and M. Heisig, "Sources of angle-dependent errors in terrestrial laser scannerbased crop stand measurement," Comput. Electron. Agric. 93, 10-16 (2013), http://dx .doi.org/10.1016/j.compag.2013.01.002.

72. K. Wang et al., "Quantification of border effect on grain yield measurement of hybrid rice," Field Crops Res. 141, 47-54 (2013), http://dx.doi.org/10.1016/j.fcr.2012.11.012.

73. N. T. My Phung, P. R. Brown, and L. K. P. Leung, "Use of computer simulation models to encourage farmers to adopt best rodent management practices in lowland irrigated rice systems in An Giang Province the Mekong Delta Vietnam," Agric. Syst. 116, 69-76 (2013), http://dx.doi.org/10.1016/j.agsy.2012.11.003.

74. Velodyne., "Velodyne HDL-64E User's Manual," http://www.velodynelidar.com/lidar/ products/manual/63-HDL64E\%20S2\%20Manual_Rev\%20D_2011_web.pdf (1 February 2014).

Nora Tilly studied geography at the University of Cologne and received her diploma in 2010. Currently, she is working in the GIS \& Remote Sensing Group at the Institute of Geography, University of Cologne. Her research interests focus on terrestrial laser scanning for agricultural applications. In this context, her $\mathrm{PhD}$ thesis is related to the International Center for AgroInformatics and Sustainable Development (ICASD).

Dirk Hoffmeister is a research assistant in the GIS \& Remote Sensing Group at the Institute of Geography, University of Cologne, where he also received his $\mathrm{PhD}$. His primary expertise is terrestrial laser scanning and corresponding applications for coastal geomorphology, agronomy, and geoarchaeology.

Biographies of the other authors are not available. 